\title{
The Psychological Synthesis Evaluated by the Interactive Model
}

\author{
A Síntese Psicológica Avaliada pelo Modelo Interativo
}

\author{
Adriana Giavoni (in memorian) ${ }^{*}, a$ \& Álvaro Tamayo (in memoriam) ${ }^{b}$ \\ ${ }^{a}$ Universidade de Brasília (UnB), Brasília, Brasil \& ${ }^{b}$ Universidade Católica de Brasília, Brasília, Brasil
}

\begin{abstract}
The purpose of this article was to elaborate a model to evaluate the synthesis process resulting from the interaction which is established between opposing constructs, like gender schemas. In social psychology, the existence of opposites is possible to be detecting in contemporary theories, such as individualism versus collectivism and masculinity versus femininity. In all these themes, opposites assume both an oppositional and complementary attitude, but little relevance has been given to the process of synthesis. The Interactive Model was elaborated in an attempt to mathematically express the synthesis process and open up the possibility of studying human personality from a new perspective - the Psychological Synthesis.

Keywords: Interactive model; Personality; Psychological synthesis; Cognitive schemas; Dualism.

Resumo

O propósito deste estudo foi elaborar um modelo para avaliar o processo de síntese resultante da interação que se estabelece entre constructos com naturezas opostas, como os esquemas de gênero. Em psicologia social, a existência dos opostos pode ser detectada em teorias contemporâneas, tais como: individualismo versus coletivismo e masculinidade versus feminilidade. Em todos estes temas, os opostos assumem tanto uma postura de oposição quanto uma postura complementar, mas pouca relevância tem sido dada ao processo de síntese. O Modelo Interativo foi elaborado na tentativa de expressar matematicamente este processo de síntese, e abre a possibilidade de se estudar a personalidade a partir de uma nova perspectiva - a Síntese Psicológica.

Palavras-chave: Modelo interativo; Personalidade; Síntese psicológica; Esquemas cognitivos; Dualismo.
\end{abstract}

The term dialectic comes from Greek, $\delta 1 \alpha \lambda \varepsilon \kappa \tau \imath \kappa \eta$, where dia "expresses the idea of duality" and lektikos means "apt to speak". The latter term comes from the same root as logos (word, reason) and, therefore, the word dialectic is understood to derive from the word dialogue, meaning more than one opinion or a duality of reasoning (Aranha \& Martins, 1989).

This term is diversely and widely used in philosophy, with four well-defined essential meanings: (a) dialectic as a method of division; (b) dialectic as probable logic; (c) dialectic as logic and; (d) dialectic as the synthesis of opposites.

The last meaning was formulated by Romantic Idealism, with Hegel as its principal exponent. Hegel, in turn, based his philosophy on Heraclitus ( $5^{\text {th }}$ century BC), in which "one constructs the demands of a reason that is at the same time a place for contradictions and their harmonious resolution" (Dumont, 2004, p. 62) and Proclus, who "defined the triadic character of the dialectic process, considering this process as deriving things from

*Address: Gislaine Melo, Universidade Católica de Brasília, Campus I, QS 07, lote 01, EPCT, Águas Claras, Brasília, DF, Brazil, CEP71966-700. Tel.: (55) 61 3356-9353/81111603.E-mail: gmelo@ucb.br the One and their return to the One" (Abbagnano, 1982, p. 255).

According to Hegel,

All reality moves dialectically and, therefore, Hegelian philosophy sees triads of thesis, antithesis and synthesis everywhere, in which antithesis represents the 'negation' or 'opposite' or 'being different' to the thesis and synthesis constitutes the unity and, at the same time, the act of making one and the other real. (Abbagnano, 1982, p. 255).

For Comparato (2006), "The Hegelian triads are not static schemas, but processes or dynamic sequences, in which the first two opposites phases are completely fulfill in a third phase" (p. 309). According to the author "all life is a permanent tension between opposite elements: universal and particular; finite and infinity ... ideal and real, divine and human" (Comparato, 2006, p. 309).

The third phase - Synthesis, is calling Aufhebung by Hegel and means "to suspend" and "to cease". This means that in the synthesis processes, the first two phases are at the same time, suspend and ceased, but in another time the synthesis could be transformed in another thesis and a new triad will be initiated. From the Hegel perspective, the dialectic processes represents the humanity evolution, including the individual, social and spiritual dimensions. 
During the life, a person could have a myriad of triads into the same dual constructs and/or in different dual constructs.

Applying this theory to psychology, the psychological synthesis could be evaluated in a dual constructs, because according to Hegel, in the synthesis, the limit imposed by each opposite are transcended, resulting in a new way of perception, free from the attributes that constitute the thesis and antithesis (Nóbrega, 2005).

In social psychology, a quick review reveals a series of contemporary theories in which opposites are present: (a) at the cultural level, in studies dealing with individualism versus collectivism (Triandis, 1989) and (b) at the individual level, in idiocentric self versus allocentric self (Triandis, Leung, Villareal, \& Clack, 1985); in individual versus social identity (Banaji \& Prentice, 1994); in the independent self versus the interdependent self (Markus \& Kitayama, 1991); agency versus communion (Helgeson, 1994); and masculinity versus femininity (Bem, 1974; Constantinople, 1973; Feather, 1978; Heilbrun \& Pitman, 1979; Orlofsky, 1977; Spence, Helmreich, \& Stapp, 1975). In all these themes, opposites assume both an oppositional and complementary posture.

Some studies have demonstrated that individuals who possess traits from constructs that form opposing pairs present differentiated cognitive, affective and behavioral responses when compared to other individuals. These differentiated responses can be observed in gender studies (Bem, 1974, 1975, 1977; Heilbrun, 1976; Lorr \& Maning, 1978; Silvern \& Ryan, 1979), more specifically in studies that deal with psychological androgyny, as well as the studies by Helgeson (1994), in which she reported that individuals who possessed agentic and communal traits presented lower disease incidences than other individuals.

It can therefore be inferred that the presence of both constructs in the individual generates a third variable synthesis, which is revealed through cognitions, affections, behaviors and attitudes, and transcend the limits imposed by each dual construct. In this way, it could be said that the individual comes to be free from the attributes that form each one of the opposite constructs, and use new variables to comprehend, feel and judge situations similar with the nature of the original constructs. As an example, the synthesis processes could be evaluated in the cognitive and affective strategies that the individual use to respond some specific event. In this kind of study, it could be analyzed if the individual use different variables to judge situations aside from those attributes that form the dual constructs.

Based on the this dialectic logic, the Interactive Model was elaborated in an attempt to mathematically express the synthesis process resulting from the interaction that is established between opposing pairs and, as an example; it was initially applied in masculine and feminine gender schemas.

\section{The Interactive Model}

\section{The Graphic Representation}

This model initially originated from a graphic representation that was similar to a $180^{\circ}$ protractor, in which two gender schemas (Masculine schema - EM and Feminine schema - EF) that formed a pair of opposites were represented, such that each schema covered a $90^{\circ}$ field. Figure 1 presents the proposed graphic representation, with the field of each schema divided into four numbered subfields.

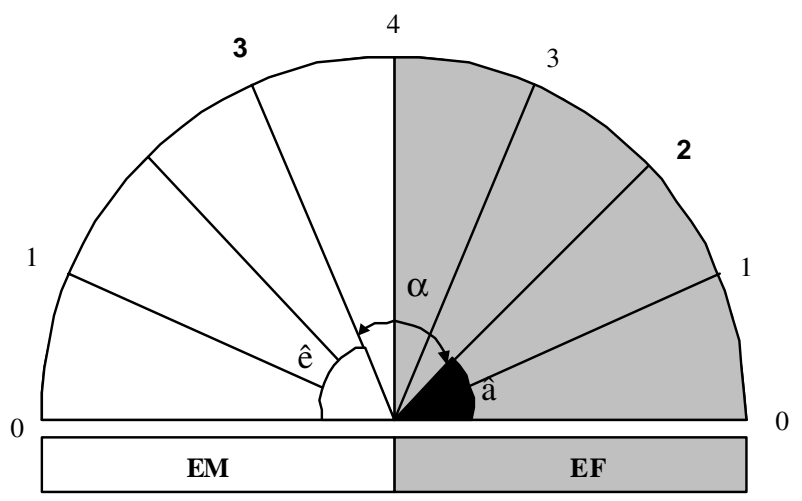

Figure 1. Graphic representation showing the schemas M and F

Thus, EM covers $0^{\circ}$ to $90^{\circ}$ and EF covers $90^{\circ}$ to $180^{\circ}$. The graphic representation permits evaluation of both $\mathrm{EM}$ and $\mathrm{EF}$ and, more importantly, permits evaluation of the interaction between the pair of opposites; an interaction that represents the dialectic synthesis process. This interaction is evaluated through the complementary angle formed between EM and EF and functions as a continuum, varying from null (0) to maximum (4). A complementary angle of $180^{\circ}$ resulting from scores of zero in both schemas (nonexistent schemas), defines the absence of interaction between the same (null interaction), while a complementary angle of $0^{\circ}$ resulting from scores of four (4.4) in both schemas, defines maximum interaction between the same (maximum interaction). Thus, the synthesis process functions from null to maximum and the graphic representation provides three scores: EM score, EF score and, most importantly, the interaction score that represents synthesis between opposites.

\section{The Mathematical Description}

Therefore, the graphic representation is a symbol of dialectic synthesis and as such, was transcribed to a mathematical language in which EM and EF become two independent dimensions that are represented by the vectors $\mathrm{EM}$ and $\mathrm{EF}$. In module, these vectors can assume infinite size, but for simplification they vary over an interval of zero to four. The vectorial sum of these vectors results in a bisector that divides the plane into two areas: EM area and EF area. Since it divides the vectorial pla- 
ne in two, each area is under the influence of a $45^{\circ}$ angle. Figure 2 presents the bisector that divides the vectorial plane in half.

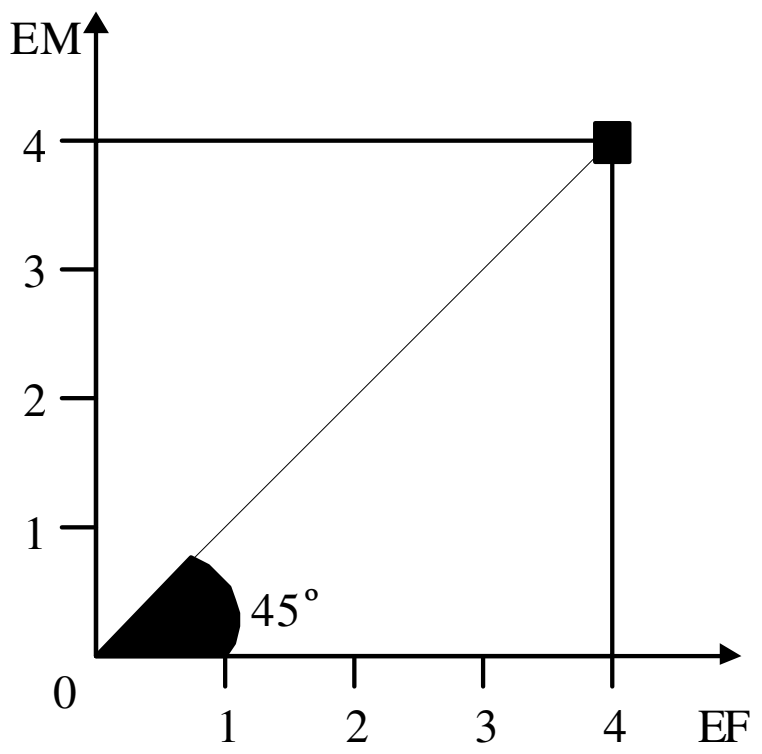

Figure 2. Bisector that divides the vectorial plane in two areas (EM and EF)
Drawing a parallel between Figure 2 and the graphic representation, the origin $(0.0)$ of this plane is found at the point of null interaction between the schemas, defining the absence of synthesis, while the ordered pair (4.4) marks the point of maximum interaction between the schemas, defining complete or maximum synthesis. The point of maximum interaction (4.4) is of fundamental importance in this model, since it describes total synthesis between opposites. As previously mentioned, this point is positioned along the bisector, forming a $45^{\circ}$ angle with the axes of EM and EF. All the points situated along the bisector are also influenced by this angle. Mathematically, this means that these points maintain certain aspects in common with one another; in this case, proportionality between schemas EM and EF. Positioning other than along the bisector represents greater dislocation towards one of the schemas in detriment to the other.

\section{The Angle Variable}

Thus, the first variable resulting from the model, and required for the process of dialectic synthesis between opposing pairs, is the Angle variable, which defines proportionality between EM and EF. Figure 3 presents the dominion of the angle variable in the vectorial plane.

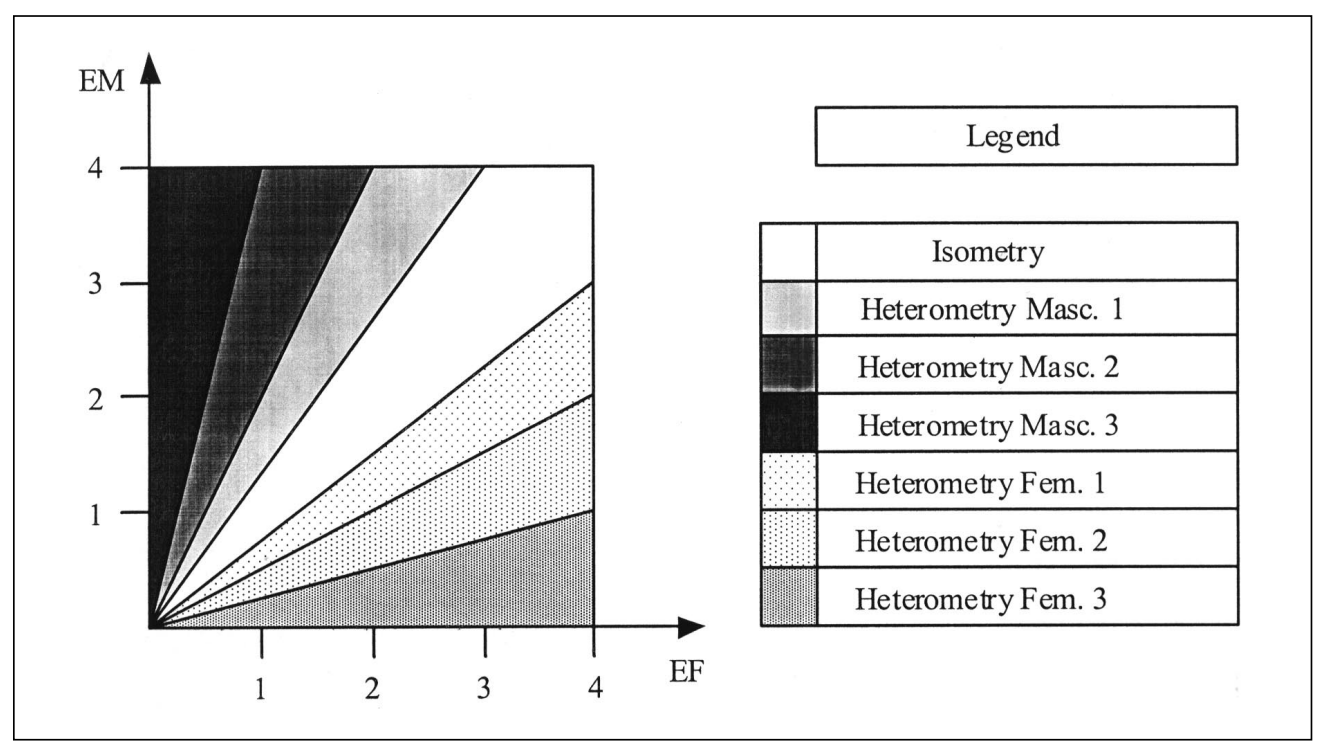

Figure 3. Fields formed by angle variable

The term Isometry was designated to define the field in which proportionality exists between EM and EF and Masculine Heterometry or Feminine Heterometry define the fields in which the predominance of EM over EF exists and vice versa, respectively. Thus, the smaller the dislocation of the ordered pair in relation to the bisector, the more isometric the schemas will be; inversely, the greater the dislocation of the ordered pair in relation to the bisector, the more heterometric the schemas will be. This is the reason that Figure 3 shows three fields for masculine heterometry and the same for feminine heterometry.

Thus, in the formation of typological groups the terms Isoschematic (Iso), Masculine Heteroschematic (MH) and Feminine Heteroschematic $(F H)$ can be respectively designated to the fields formed in the vectorial plane according to the influence of the angle variable.

However, given that the angle variable is important for the synthesis process, how the individual could be classified into the typological groups formed by this variable? 
To classify the individuals into gender schemas typological groups it was elaborated and validated the Masculine Inventory of the Self-Concept's Gender Schemas ([IMEGA], Giavoni \& Tamayo, 2003) to be applied in males and Feminine Inventory of the Self-Concept's Gender Schemas ([IFEGA], Giavoni \& Tamayo, 2005) to be applied in females.

As an example, the IFEGA was composed by two scales - masculine scale formed by Audacity, Egocentrism and Negligence factors and the feminine scale, formed by Sensuality, Inferiority and Social Adjustment factors. Two vectors result from these factors - Masculine Vector (MV) and Feminine Vector (FV). These vectors are mathematical representations from the level of development that exist in masculine and feminine schemas. The masculine vector (MV) and feminine vector (FV) can be obtained by the equations:

$$
\begin{aligned}
& \mathrm{MV}=\sqrt{\sum(\text { Audacity })^{2}+\left({\text { Egocentrism })^{2}+(\text { Negligence })^{2}}^{2}\right.} \\
& \mathrm{FV}=\sqrt{\sum(\text { Sensuality })^{2}+(\text { Inferiority })^{2}+(\text { SocialAdjustment })^{2}}
\end{aligned}
$$

From the scores obtained by these vectors (MV; FV), the individual could be inserted in the vectorial plane. Once in the vectorial plane, it is necessary evaluate the dislocation between the point where the individual is inserted (MV; FV) and the bisector that divides the plane in two areas - masculine area and feminine area. Figure 4 presents the vector $\mathrm{Vi}$, whose angle $e$ can be obtained by the tangent of the right triangle, whose catheti are the vectors MV (2) and FV (3).

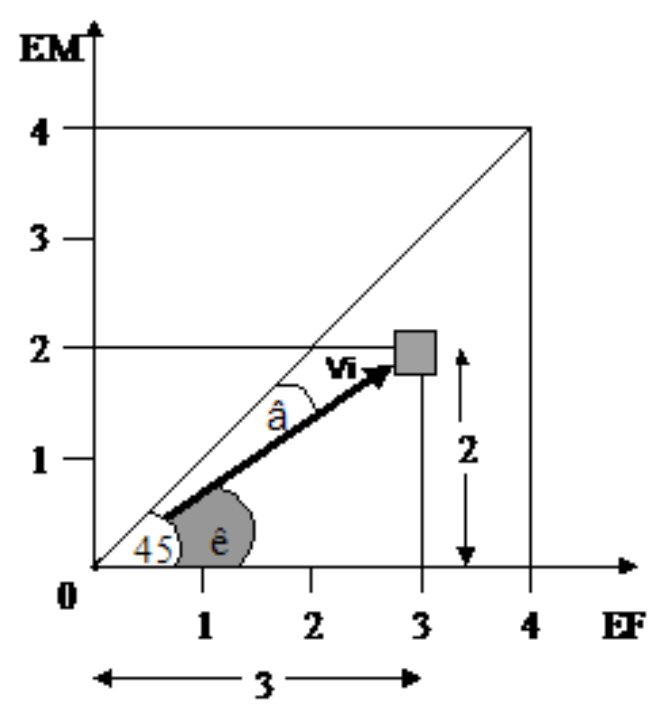

Figure 4. Dislocation of vector Vi (Angle a) in relation to the bisector

Thus, $\mathrm{Tg} e=\mathrm{MV} / \mathrm{FV}$. It is known that the bisector forms a $45^{\circ}$ angle with the axes. Angle $a$ is obtained by subtraction between the $45^{\circ}$ angle and the arctangent of $e$. Thus, $a=45^{\circ}-\operatorname{arctg} e$. Angle $a$ represents the dislo- cation of vector $\mathrm{Vi}$ in relation to the bisector. Using this evaluation method, the dislocation of any individual positioned in the vectorial plane can be determined.

\section{The Distance Variable}

A second variable derived from the model and important for the synthesis process was denominated Distance. Although all ordered pairs situated along the bisector present proportionality between the schemas, these pairs are situated at different distances from the point of maximum interaction. For example, the ordered pair (3.3) is found at a shorter distance from the point of maximum interaction than the ordered pair (1.1). The magnitude of the vectors EM and EF that form the ordered pair (3.3) are greater than the magnitude of the same vectors of the ordered pair (1.1).

Thus, the greater the magnitude of the vectors that form the ordered pair, the shorter the distance that separates them from the point of maximum interaction, in which vectors EM and EF achieve their greatest magnitude. Hence, a new important variable appears regarding the synthesis process, denominated the distance variable. The fields defined by this variable were denominated Micrometry and Macrometry. Figure 5 presents the dominions of the distance variable.

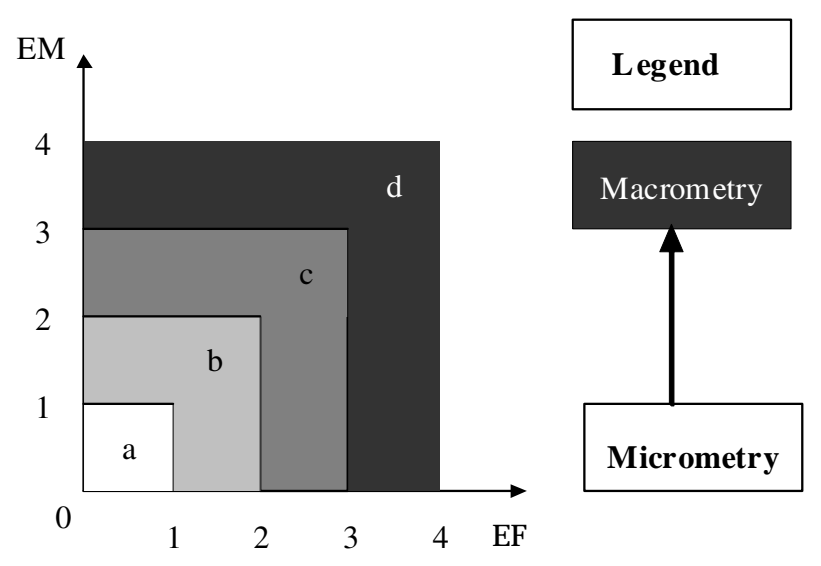

Figure 5. Fields formed by distance variable

Micrometric fields define individuals that present poorly developed or rudimentary cognitive schema, formed by few elements and, therefore, of low complexity, while macrometric schema consist of many elements, revealing high complexity and development. As a function of schema complexity, individuals presenting micrometric schema were denominated Simple and individuals presenting macrometric schema were denominated Complex.

Given that the distance variable is important for the synthesis process, because it defines the complexity of schemas development, how can be determined the distance of the individuals positioned over the vectorial plane? Figure 6 presents the ordered pair (3.2), represented by vector $\mathrm{Vi}$. 


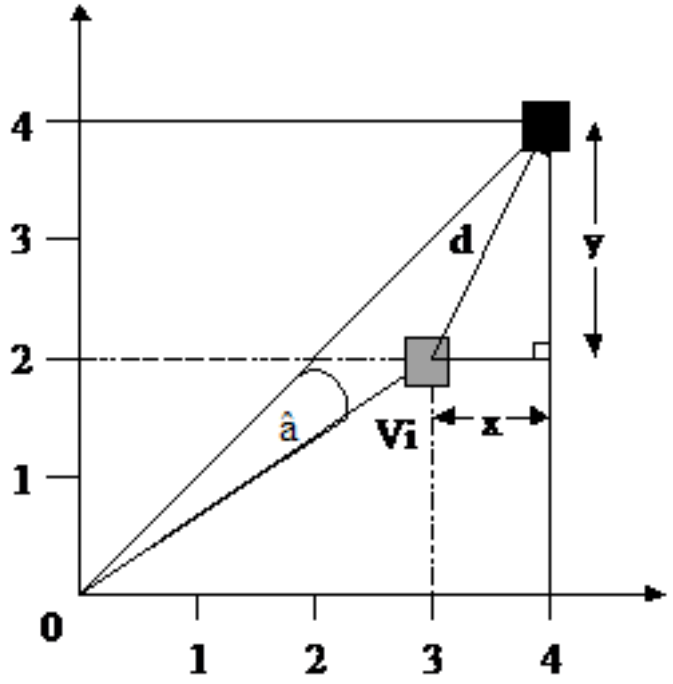

Figure 6. Distance determination for the ordered pair (3.2) in relation to maximum interaction point $(4,4)$

The variable distance $d$ is the hypotenuse of a right triangle, whose catheti are X (1) and Y (2). By applying Pythagoras' theorem, the value of distance $d$ is determined. Thus, $d^{2}=\sqrt{(X)^{2}+(Y)^{2}}$. Using this method, the value of the distance variable at any point on the vectorial plane can be determined.

\section{The Synthesis Variable}

Thus, two variables are important for the process of synthesis, the angle and distance variables, which respectively define the relations of proportionality and magnitude between such pairs. The intersection of these two variables in the vectorial plane produces a series of fields, as shown in Figure 7.

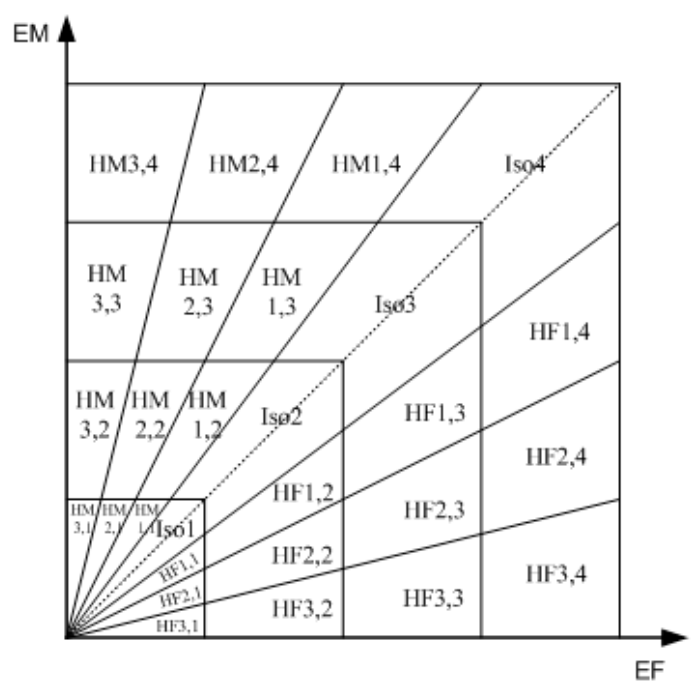

Figure 7. Final fields formed by the intersection of the angle and distance variables

Note. Angle variable: HM3, HM2, HM1, ISO, HF1, HF2, HF3. Distance variable: fields varying from the 1 (next to the origin) to 4 (extreme field).
These fields vary in proportionality and magnitude, but above all, these pairs vary regarding the process of synthesis, which determines perceptive, cognitive, affective and behavioral differences between typological groups positioned in the fields that constitute the model.

Synthesis evaluation occurs through projection of the representative pair ordered vector onto the bisector. Figure 8 presents vector $\mathrm{V}(\mathrm{MVi} ; \mathrm{FVj})$ projected onto the bisector.

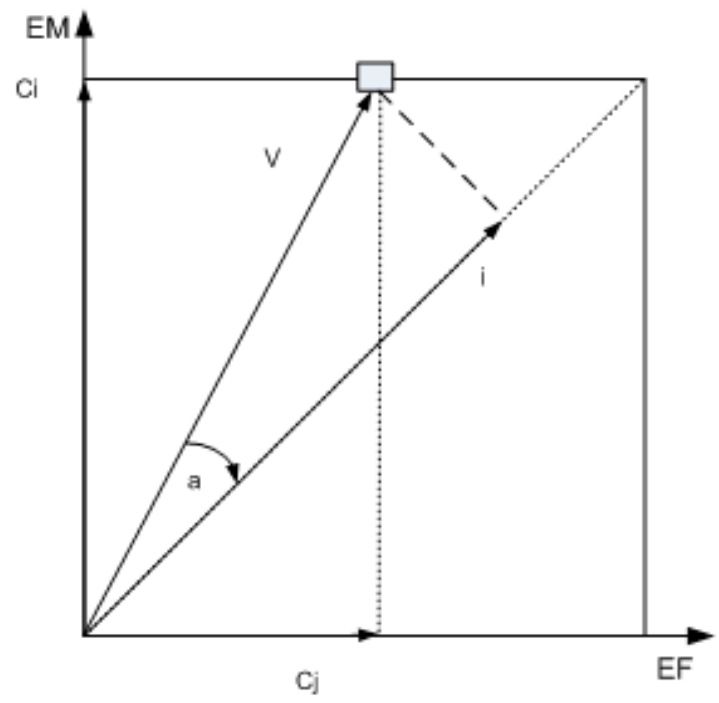

Figure 8. Vector $\mathrm{V}(\mathrm{Ci} ; \mathrm{Cj})$ projected onto the bisector

Projection of vector $\mathrm{V}$ onto the bisector, results in vector i. The magnitude of this vector defines the level of synthesis (S) of the ordered pair $(\mathrm{MVi} ; \mathrm{FVj})$ and can be obtained using the following equation:

$$
S=\sqrt{(M V)^{2}+(F V)^{2}} \times \cos a
$$

In Figure 8, it can be observed that as the ordered pair distances itself from the bisector, synthesis is diminished and vice versa. Thus, individuals positioned in masculine or feminine heterometric fields, when projected onto the bisector, will never achieve the process of total synthesis, presenting at most, moderate or incomplete synthesis.

The model demonstrates that to achieve a process of total or complete synthesis requires that both schemas have developed in a complete and balanced manner, generating a third variable, which "configure as true and independent realities". It is very probably that in the synthesis processes, the development of the schemas diminishes stereotypic concepts regarding the same, leaving the individual free to judge situations beyond their dominion. A parallel can be made of the effect of schema development with studies by Moscovici (1961), in which the author demonstrated that the degree to which knowledge of a given object increases, the objectification of the same diminishes. 
Behavioral flexibility and the freedom to judge certain situations using parameters distinct from those circumscribed by the schemas were amply observed in a number of studies involving psychological androgyny (Bem, 1974, 1975, 1977; Heilbrun, 1976; Heilbrun \& Pitman, 1979; Helmreich, Spence, \& Holahan, 1979; Kalin, 1979; Spence et al., 1975).

Originally proposed by Bem (1974), androgyny is conceived as resulting from the balanced development of masculine and feminine characteristics in the same individual. Structuring the Balanced Model from a bidimensional concept of masculinity and femininity, this model classified the subjects into three typological groups, denominated Masculine, Feminine and Androgynous, such that the last group consisted of individuals that presented equilibrium between masculine and feminine traits.

When applying the Interactive Model in this context, observation reveals that the angle variable presents a strong correspondence with this model. The groups masculine, androgynous and feminine present a direct ideological correspondence with the three principal types of the Interactive Model, denominated masculine heteroschematic, isoschematic and feminine heteroschematic, respectively.

Later studies resulted in other models; both the Additive Model (Spence et al., 1975) and the Unidimensional Model (Heilbrun \& Pitman, 1979) are relevant to the present argument and should be highlighted, each seeks to explain and complement different concepts of androgyny. For the Additive Model (Spence et al., 1975), androgyny results from the high magnitude that masculinity and femininity assume in the individual, generating four psychological groups denominated masculine, feminine, undifferentiated and androgynous.

In the Interactive Model, the distance variable, which defines the magnitude or level of schema development, relates to this model (Spence et al., 1975), The distance variable delimits fields that vary from micrometry to macrometry, resulting in four principal combinations when considering the opposing pair: (a) masculine micrometry- feminine micrometry; (b) masculine micrometry-feminine macrometry; (c) masculine macrometry-feminine micrometry; and (d) masculine macrometry-feminine macrometry. These four combination types respectively possess direct ideological correspondence with the Additive Model groups undifferentiated, feminine, masculine and androgynous.

For the Unidimensional Model (Heilbrun \& Pitman, 1979), androgyny is conceived as a continuous variable, with its limits defined as zero androgyny and total androgyny. Through the fusion of the Balanced Model with the Additive Model, androgyny can be evaluated by the following mathematic expression: $\mathrm{A}=(\mathrm{M}+\mathrm{F})-(\mathrm{M}-$ F). This concept of androgyny determines that the same is the result of proportionality and the level of schema development and that the level of androgyny in an individual can be evaluated by this relation. This concept presents a strong relation with the synthesis variable of the Interactive Model, which also results from the interaction between schema proportionality and development. Similarly, this variable functions between null and maximum values, in which it is possible to evaluate the level of synthesis between opposing pairs in all individuals.

Given that the studies were based on opposing concepts, as is the case of masculinity and femininity, it can be assumed that the phenomenon of androgyny observed in the individuals classified as androgynous are reflexes of the process of synthesis that occurs between the opposing pairs masculinity-femininity. These individuals presented behavioral flexibility and the freedom to judge certain situations using parameters distinct from those circumscribed by the masculinity and femininity.

Thus, applying the Interactive Model in the dialectic concept of masculinity-femininity, androgyny could be conceived as the process of synthesis that occurs between these schemas. Given the correspondence between the Balanced and Additive Models and the Interactive Model, it can be inferred that the masculine heteroschematic and feminine heteroschematic present the same psychological profile as the type's masculine and feminine of these other models.

This means that due to the heterometry between these schemas, these individuals will tend to: (a) memorize with greater facility words that are consistent with the predominant schema and present difficulty in memorizing words that are consistent with the nonpredominant schema; (b) present a shorter latency period when judging, characteristics consistent with the predominant schema and a longer latency period when judging characteristics consistent with the nonpredominant schema; (c) engage in activities consistent with the predominant schema and avoid those consistent with the nonpredominant schema; (d) use nonverbal signals consistent with the predominant schema; and (e) perceive others according to the predominant schema (Bem, 1975, 1977, 1981; Bem \& Lenney, 1976; Bem, Martyna, \& Watson, 1976; Frable, 1989; Frable \& Bem, 1985; Helmreich et al., 1979; LaFrance \& Carmen, 1980; Lippa, 1977, 1978; Markus, Crane, Berrnstein, \& Siladi, 1982; Mills, 1983).

Similarly, the isometry field permits the postulation that Isoschematic individuals do not present the tendencies cited above, since these individuals do not possess predominance of one schema over the other. Isometry explains the absence of significant differences found for the androgyny and undifferentiated groups in relation to the above cited items, since both these types of individuals present proportionality between masculinity and femininity (Andersen \& Bem, 1981; Bem, 1981; Bem et al., 1976; Frable, 1989; Helmreich et al., 1979; LaFrance \& Carmen, 1980; Lippa, 1977, 1978, 1983; Markus et al., 1982; Mills, 1983). 
Studies using the angle variable reveal that the female masculine heteroschematic and isoschematic gained greater muscular resistance and maximum strength when compared to feminine heteroschematic. The former group also presented greater satisfaction regarding maximum strength training (Custódio \& Giavoni, 2010). In another study (Gomes \& Giavoni, 2010), males masculine heteroschematic presented more fatigue than the isoschematic and feminine heteroschematic groups. In the assessment of six sprints executed by the athletes, it was observed that masculine heteroschematic and isoschematic presented more variation between the initial and final maximum potency, when compared with the feminine heteroschematic. These results confirm that the typological groups engage in activities consistent with the predominant schema and showing more motivation in these activities.

Concerning the distance variable, it can be postulated that, psychologically, this variable determines the behavioral consistency of individuals, since it is related to the level of schema development. This hypothesis is based on the work of Markus et al. (1982), who evaluated the differences that exist between the androgyny and undifferentiated groups. According to the authors, these two groups differ only regarding the reliability of their replies; the replies of the androgyny group are more consistent than those given by the undifferentiated group. According to the Interactive Model, these two groups present masculine macrometric-feminine macrometric and masculine micrometric-feminine micrometric constructs, respectively. Thus, they differ concerning the level of schema development.

Studies realized by Rushton, Jackson and Paunonen (1981) confirm the existence of a positive correlation between the level (score) designated to a given trait and the behavioral consistency in relation to the same. The higher the score designated to the trait, the greater the behavioral consistency of the individual in relation to that trait and vice versa.

Based on previous studies, therefore, it can be postulated that the cognitive, affective and behavioral responses of the typological groups of the Interactive Model will differ, as will their consistency. However, the responses will tend to be more flexible and disentailed from the dominion of the schemas as these present a greater level of development and greater approximation with an isometric situation. These conditions assure a more complete process of synthesis, reflected in the individual responses.

While transiting between null and maximum, the Interactive Model bisector reflects the different gradations of dialectic synthesis that exist between opposing pairs. Along this bisector, innumerous possible situations can be found from an ideal situation of nonexistent schemas, passing through situations of rudimentary schemas that can be symmetric or asymmetric and gradually transiting toward a situation in which the schemas develop in symmetric or asymmetric manner.
Thus, it is the level of dialectic synthesis that predisposes the individual to a particular type of perception and, consequently, to conception. The perceptions of individuals presenting asymmetric rudimentary schemas tend to be ruled by the dominant schema, which due to the low level of development, tends to result in inconsistent responses and a unidimensional concept of the opposing pair.

The same occurs for individuals presenting symmetrical rudimentary schemas, although these present a slightly differentiated perception from the first group due to the influence of two constructs. Even so, they tend to present inconsistent responses and perceive the opposing pair as dichotomic constructs (unidimensional), comprehending a single point on this continuum.

To the degree that the schema develop, synthesis between the schemas increases, leading the individual toward a bidimensional concept of the same, since they recognize and accept in themselves aspects of both schemas. However, asymmetric development of one schema in detriment to the other, eventually determines individual perception in favor of the predominant schema. Thus, the cognitive, affective and behavioral responses of these individuals are still ruled by the predominant schema, with the perception of attributes pertaining to the nondominant schema relegated to projections, stereotypes and/or prejudices.

With the gradual development of the schema, these become more "fluid and flexible", possibly more permeable, liberating the individual from being circumscribed by their content. This is the point in which the process of synthesis becomes more evident, since these individuals use other parameters to reflect on and judge situations. It can be inferred that at this level of synthesis, the initial dualism has been transcended, presenting a third variable that, while it does not annul the first two, provides a new form of conduct in relation to the pair of opposites.

The individual's perceptions in the bisector are analogous to the photograph enlargement. If a black and white photo is reduced, the image turns a blot and if enlarged the images disappeared, due to the large distance between black and white points. There is a range where it is possible to see the image, but in the extremities it is impossible. The same occur in the schemas. In the origin, there are no schemas, so there is no image about the constructs. During a interval, where the schemas become more developed, the image is a objectification - a stereotyped image, and when the schemas become well developed, the images disappeared because the degree to which knowledge of a given object increases, the objectification of the same diminishes.

This concludes the presentation of the Interactive Model, a model that is proposed for the study of psychological synthesis, a process resulting from dialectic synthesis pertaining to constructs presenting opposing concepts, which are frequently found in Psychology. Thus, the Interactive Model opens up the possibility of studying 
human behavior from a new perspective, foreseeing in dialectic synthesis the cognitive, affective and behavioral differences found in individuals and, moreover, revealing that with increased synthesis between opposing pairs, the individual achieves a third perceptive plane, in which they are liberated from the rigid impervious concepts circumscribed by the constructs that form the pair of opposites.

\section{References}

Abbagnano, N. (1982). Dicionário de filosofia [Philosophy dictionary]. São Paulo, SP: Mestre Jou.

Andersen, S. M., \& Bem, S. L. (1981). Sex typing and androgyny in dyadic interaction: Individual differences in responsiveness to physical attractiveness. Journal of Personality and Social Psychology, 41, 74-86.

Aranha, M. L. A., \& Martins, M. H. P. (1989). Filosofando: Introdução à Filosofia [Philosophizing: Introduction to Philosophy]. São Paulo, SP: Moderna.

Banaji, M. R., \& Prentice, D. A. (1994). The self in social contexts. Annual Review of Psychology, 45, 297-332.

Bem, S. L. (1974). The measurement of psychological androgyny. Journal of Consulting and Clinical Psychology, 42, 155-162.

Bem, S. L. (1975). Sex role adaptability: One consequence of psychological androgyny. Journal of Personality and Social Psychology, 31, 634-643.

Bem, S. L. (1977). On the utility of alternative procedures for assessing psychological androgyny. Journal of Consulting and Clinical Psychology, 45, 196-208.

Bem, S. L. (1981). Gender schema theory: A cognitive account of sex typing. Psychological Review, 88, 354-364.

Bem, S. L., \& Lenney, E. (1976). Sex typing and the avoidance of cross-sex behavior. Journal of Personality and Social Psychology, 33, 48-54.

Bem, S. L., Martyna, W., \& Watson, C. (1976). Sex typing and androgyny: Futher explorations of the expressive domain. Journal of Personality and Social Psychology, 34, 10161023.

Comparato, F. K. (2006). Ética [Ethics]. São Paulo, SP: Companhia das Letras.

Constantinople, A. (1973). Masculinity - femininity: An exception to a famous dictum. Psychological Bulletin, 80, 389-407.

Custódio, M. R. M., \& Giavoni, A. (2010). Differences in muscular resistance and maximum strength acquisition between gender schema typological groups. Manuscript submitted for publication.

Dumont, J. P. (2004). Elementos de história da filosofia anti$g a$ [History elements from the greek philosophy]. Brasília, DF: Editora da Universidade de Brasília.

Feather, N. T. (1978). Factor structure of the Bem Sex-Role Inventory: Implications for the study of masculinity, femininity, and androgyny. Australian Journal of Personality, 30, 241-254.

Frable, D. E. S. (1989). Sex typing and gender ideology: Two facets of the individual's gender psychology that go together. Journal of Personality and Social Psychology, 56, 95-108.
Frable, D. E. S., \& Bem, S. L. (1985). If you are gender schematic, all members of the opposite sex look alike. Journal of Personality and Social Psychology, 49, 459-468.

Giavoni, A., \& Tamayo, A. (2003). Inventário masculino dos esquemas de gênero do autoconceito (IMEGA) [Masculine Inventory of the Self-Concept's Gender Schemas]. Psicologia: Teoria e Pesquisa, 19, 249-259.

Giavoni, A., \& Tamayo, A. (2005). Inventário Feminino dos Esquemas de Gênero do Autoconceito (IFEGA) [Feminine Inventory of the Self-Concept's Gender Schemas]. Estudos de Psicologia (Natal), 10, 25-34.

Gomes, S. A., \& Giavoni, A. (2010). Avaliação da composição corporal e dos níveis de aptidão física de atletas de futsal classificados segundo a tipologia dos esquemas de gênero [Body composition and physical fitness level evaluation among futsal athletes classified into gender schemas typological group]. Manuscript submitted for publication.

Heilbrun, A. B. (1976). Measurement of masculine and feminine sex role identities as independent dimensions. Journal of Consulting and Clinical Psychology, 44, 183190.

Heilbrun, A. B., \& Pitman, D. (1979). Testing some basic assumptions about psychological androgyny. The Journal of Genetic Psychology, 135, 175-188.

Helgeson, V. S. (1994). Relation of agency and communion to well-being: Evidence and potential explanations. Psychological Bulletin, 116, 412-428.

Helmreich, R. L., Spence, J. T., \& Holahan, C. K. (1979). Psychological androgyny and sex role flexibility: A test of two hypotheses. Journal of Personality and Social Psychology, 37, 1631-1644.

Kalin, R. (1979). Method for scoring androgyny as a continuous variable. Psychological Reports, 44, 1205-1206.

LaFrance, M., \& Carmen, B. (1980). The nonverbal display of psychological androgyny. Journal of Personality and Social Psychology, 38, 36-49.

Lippa, R. (1977). Androgyny, sex-typing, and the perception of masculinity-femininity in handwritings. Journal of Research in Personality, 11, 21-37.

Lippa, R. (1978). The naive perception of masculinityfemininity on the basis of expressive cues. Journal of Research in Personality, 12, 1-14.

Lippa, R. (1983). Sex typing and the perception of body outlines. Journal of Personality, 51, 667-682.

Lorr, M., \& Manning, T. T. (1978). Personality correlates of the sex role types. Journal of Clinical Psychology, 34, 884888.

Markus, H., Crane, M., Bernstein, S., \& Siladi, M. (1982). Self-schemas and gender. Journal of Personality and Social Psychology, 42, 38-50.

Markus, H., \& Kitayama, S. (1991). Culture and the self: Implications for cognition, emotion, and motivation. Psychological Review, 98, 224-253.

Mills, C. J. (1983). Sex-typing and self-schema effects on memory and response latency. Journal of Personality and Social Psychology, 45, 163-172.

Moscovici, S. (1961). La psychanalyse, son image et son public. Paris: Press Universitary de France.

Nóbrega, F. P. (2005). Compreender Hegel. Petrópolis, RJ: Vozes. 
Orlofsky, J. L. (1977). Sex-role orientation, identity formation, and self-esteem in college men and women. Sex Roles, 3, 561-575.

Rushton, J. P., Jackson, D. N., \& Paunonen, S. V. (1981). Personality: Nomothetic or idiographic? A response to Kenrick and Stringfield. Psychological Review, 88, 582-589.

Silvern, L. E., \& Ryan, V. L. (1979). Self-rated adjustment and sex-typing on the Bem Sex-Role Inventory: Is masculinity the primary predictor of adjustment? Sex Roles, 5, 739-763.

Spence, J. T., Helmreich, R., \& Stapp, J. (1975). Ratings of self and peers on sex role attributes and their relation to self-esteem and conceptions of masculinity and femininity. Journal of Personality and Social Psychology, 32, 29-39.

Triandis, H. C. (1989). The self and social behavior in differing cultural contexts. Psychological Review, 96, 506-520.

Triandis, H. C., Leung, K., Villareal, M., \& Clack, F. L. (1985). Allocentric versus idiocentric tendencies: Convergent and discriminant validation. Journal of Research in Personality, 19, 395-415. 